\title{
A critical perspective on early communications concerning human health aspects of microplastics
}

Rist, Sinja; Carney Almroth, Bethanie; Hartmann, Nanna B.; Karlsson, Therese M.

\section{Published in:}

Science of the Total Environment

Link to article, DOI:

10.1016/j.scitotenv.2018.01.092

Publication date:

2018

Document Version

Peer reviewed version

Link back to DTU Orbit

Citation (APA):

Rist, S., Carney Almroth, B., Hartmann, N. B., \& Karlsson, T. M. (2018). A critical perspective on early communications concerning human health aspects of microplastics. Science of the Total Environment, 626, 720726. https://doi.org/10.1016/j.scitotenv.2018.01.092

\section{General rights}

Copyright and moral rights for the publications made accessible in the public portal are retained by the authors and/or other copyright owners and it is a condition of accessing publications that users recognise and abide by the legal requirements associated with these rights.

- Users may download and print one copy of any publication from the public portal for the purpose of private study or research.

- You may not further distribute the material or use it for any profit-making activity or commercial gain

- You may freely distribute the URL identifying the publication in the public portal 


\section{A critical perspective on early communication concerning 2 human health aspects of microplastics}

3

4

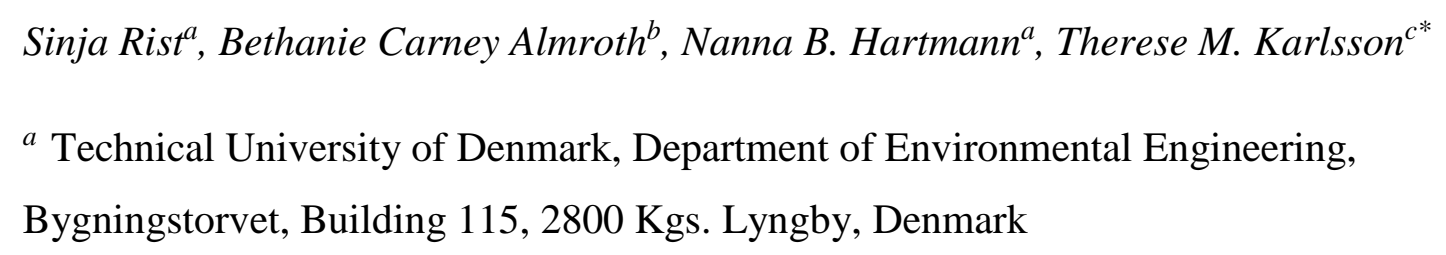

${ }^{*}$ Corresponding author: therese.karlsson@marine.gu.se

\section{Abstract}

Microplastic research in recent years has shown that small plastic particles are found almost everywhere we look. Besides aquatic and terrestrial environments, this also includes aquatic species intended for human consumption and several studies have reported their prevalence in other food products and beverages. The scientific as well as public debate has therefore increasingly focused on human health implications of microplastic exposure. However, there is a big discrepancy between the magnitude of this debate and actual scientific findings, which have merely shown the presence of microplastics in certain products. While plastics can undoubtedly be hazardous to human health due to toxicity of associated chemicals or as a consequence of particle toxicity, the extent to which microplastics in individual food products and beverages contribute to this is debatable. Considering the enormous use of plastic materials in our everyday lives, microplastics from food products and beverages likely only constitute a minor exposure pathway for plastic particles and associated chemicals to humans. But as this is rarely put into perspective, the recent debate has created a skewed picture of human plastic exposure. We risk pulling the focus away from the root of the problem: the way in which we consume, use and dispose of plastics leading to their widespread presence in our everyday life and in the environment. Therefore we urge for a more careful and balanced discussion which includes these aspects. 


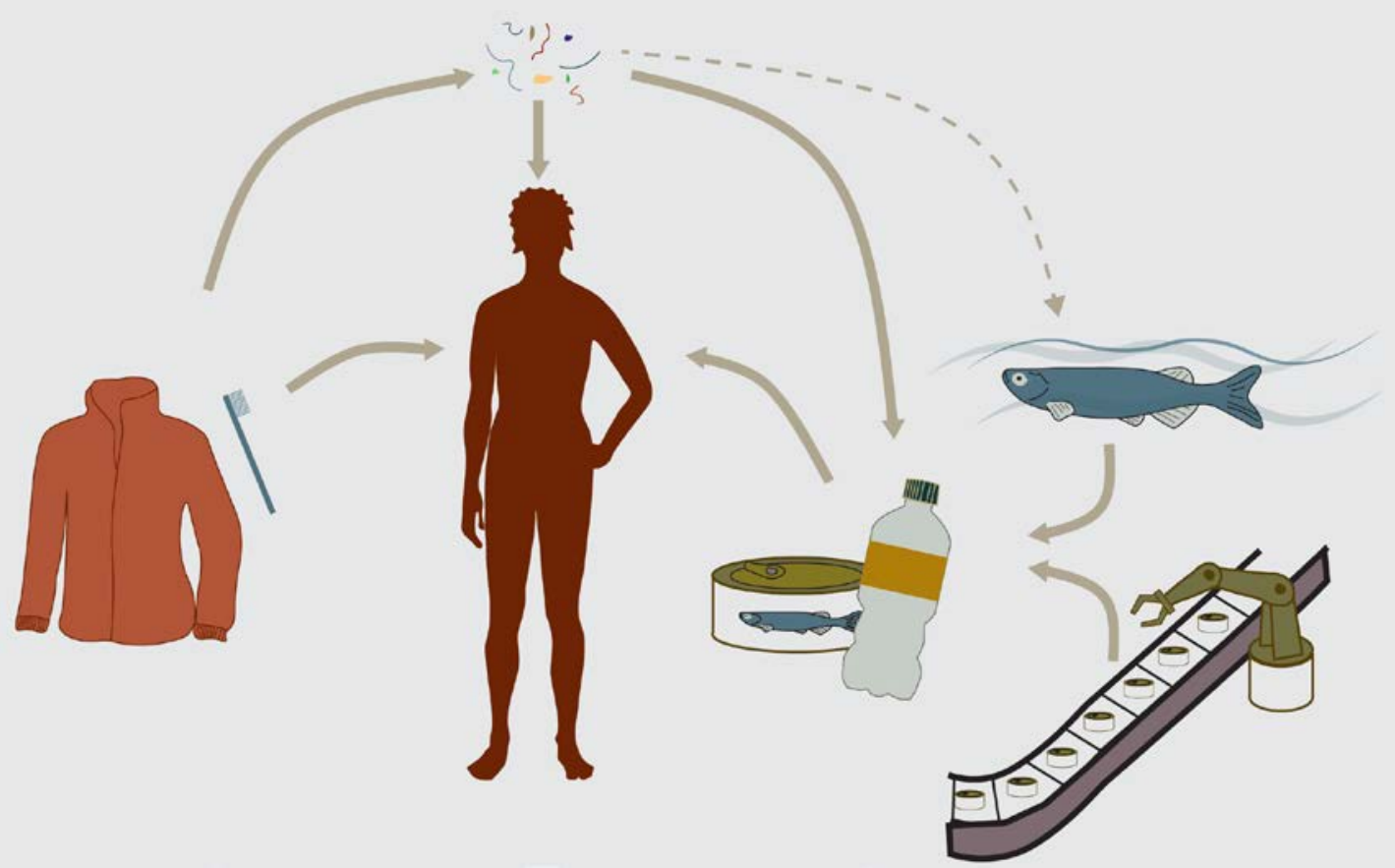

Keywords

contamination, food products, plastic additives, chemical toxicity, particle toxicity

\section{Highlights}

- There is data supporting possible chemical and particle toxicity effects of plastic

- The current debate on human health effects of plastics is unbalanced

- There is a disproportionate focus on microplastics in individual food products

- Exposure to additives and microplastics is mainly related to general plastic use

- We urge for a more balanced discussion on human exposure to plastics 


\section{Introduction}

An increasing number of studies show that plastics in general, and microplastics in particular, are ubiquitous in all environmental compartments, including sediments, soils, water columns and surface layers in marine and freshwater systems (Li et al., 2016; van Sebille et al., 2015). It seems that wherever we look we find plastics, and some of the supposed sources include abrasion of plastic products and paints (Lassen et al., 2015), fragmentation of mismanaged plastic waste, discarded/lost fishing equipment (Andrady, 2011), and microplastic fibers from textiles (Browne et al., 2011). Plastic pollution is thus mainly a diffuse source problem. However, major pathways for release into the environment have been identified and include WWTP effluents and storm water drains (Lattin et al., 2004; van Wezel et al., 2015). Although plastic pollution may cause adverse effects in all environmental compartments the ecological effects of plastic pollution have so far mainly been studied in marine environments where numerous species of birds, fish and invertebrates have been found to ingest macro- and microplastics (GESAMP, 2015) and over 800 species are known to be affected by marine litter (UNEP, 2016). Field measurements have also shown their presence in marine species used for human consumption, like bivalves and fish (Dehaut et al., 2016; Rochman et al., 2015). Furthermore, microplastics have been reported in tap water, bottled water, sugar, salt, beer and honey (Karami et al., 2017; Kosuth et al., 2017; Liebezeit and Liebezeit, 2014, 2013; Schymanski et al., 2017; Yang et al., 2015). The issue of microplastic contamination in food products and beverages has gained increasing public interest and media attention in recent years, triggering the logical question: are there implications for human health? This concern likely results from a synthesis of different inputs: the easily identifiable environmental pollution associated with macroplastic littering and mismanaged waste, a fear of the seemingly omnipresent and invisible microplastics, and finally the well-known harmful effects of some plastic additives and plasticizers such as for example phthalates. In combination, this has led to numerous publications (both scientific and popular) speculating about the human health consequences of microplastic exposure. There is, however, a large discrepancy between the current state of scientific evidence concerning effects of microplastics and the ongoing public discussion and subsequent fears, leading to a potentially incorrect focus and path forward. We will explain why this is problematic.

Since their first commercial production in the mid-20 ${ }^{\text {th }}$ century plastics have revolutionized society; from healthcare to food safety and transport (Andrady and Neal, 2009). In fact, plastics have allowed for a technological leap in many areas directly or indirectly related to 
human health. Conversely, plastic materials have the potential to pose or contribute to direct or indirect human health risks. Plastic bags have for example been seen to provide breeding habitats for mosquitoes carrying malaria (Njeru 2006) or causing flooding by blocking drains as it happened in Bangladesh in 2002 (NOLAN-ITU, 2002). Plastic materials are also associated with thousands of chemicals; several of which are found in human blood, urine and breastmilk and some of which are known to have adverse effects on animals and potentially humans (Talsness et al., 2009). There are many areas in the world that lack proper waste management, which often results either in the creation of vast landfills or in a routine burning of waste. When incinerated, plastic materials have long been known to release polycyclic aromatic hydrocarbons (PAHs) (Li et al., 2001) and toxic gases, for example furan and dioxin (Menad et al., 1998). Moreover they can leave residues of lead and cadmium (Korzun and Heck, 1990), two metals known to be toxic to human health. A more recently explored aspect of plastic-related human health effects concerns particles in the micro- and nano-scale, which are either intentionally produced in that size or created through the fragmentation of larger plastics. Potential effects of such particles have to a degree been studied in the field of arthroplasty where plastic prosthesis have been shown to fragment, creating small plastic particles (Hicks et al., 1996). Human health effects of particles in general have also been extensively documented within the field of air pollution (Chen et al., 2016; Stone et al., 2007).

As noted above there are a number of reasons to assume that plastic materials, as we use and dispose of them today, may pose risks to human health. While pollution in general is recognized as a major contributor to human disease and premature death (Landrigan et al., 2017), many research scientists express a mixture of skepticism and concern over the extent and associated human health risks of plastic pollution as a whole (Seltenrich, 2015). Nevertheless, human health effects of specifically microplastics have been the primary focus of the recent public debate. These public concerns are largely linked to potential exposure to microplastic contaminants in food and beverages, for example in seafood or tap water, even though these are not likely to be among the major exposure pathways of microplastics and associated chemicals to humans. Plastics are such an integrated part of our everyday lives that the few added fibers or particles that may occur in some food products or beverages are likely not even comparable to the quantity of plastic materials and chemicals that we are exposed to through our usage of clothes, food contact materials, packaging, building materials and kitchen appliances. In fact, it is reasonable to assume that the amount of microplastic fibers that is reportedly found in tap water may be equivalent to the amount that ends up in a glass of 
water standing on a kitchen counter as a result of settling of dust or air particulate matter which consists largely of microplastic fibers from clothing. Somewhat ironically, this widespread occurrence of microplastics is why researchers face such challenges in avoiding sample contamination even in the cleanest lab environments. Still, the potential human health risks of microplastics in food products and beverages are often exaggerated, even in the scientific literature (Koelmans et al., 2017), not surprisingly leading to strong reactions in public media.

Plastics in the environment comprise a 'wicked problem' (Hastings and Potts, 2013), complicated by numerous stakeholders, as well as complex moral, ethical and political considerations. Through focusing on the risk of microplastics in specific food items, such as seafood or tap water, we risk pulling focus away from the root of the problem, namely the way that we produce, use and dispose of plastic materials in modern society. While research into fate, effects and consequences of microplastics is warranted, here we focus on the contrast between the current debate of microplastics as a potential human health hazards and known health effects of plastic materials and associated chemicals. Moreover, we want to draw attention to the manner in which scientific results of this field are communicated within the scientific community as well as to the general public. We urge for a more balanced and careful interpretation of findings. Lastly, we want to encourage a discussion on how our consumption, use and disposal of plastics may fit into the debate on human health effects.

\section{Potential mechanisms of plastic-related adverse effects on human health}

\subsection{Toxicity of chemicals in plastic products}

Plastic materials are made from mono- or oligomeric building blocks arranged through different techniques and chemical reactions into polymeric chains. In order to create the many different types of plastics with differing properties that we see on the market today, the industry also makes use of a wide array of plastic additives including different types of fillers, flame retardants, antioxidants, plasticizers and colorings (Halden, 2010). The produced materials will contain a majority of polymeric chains, but also some residual monomers, catalyzing agents used in the chemical processing, additives and potentially non-intentionally added substances carried over from the raw materials (usually petroleum oil). Overall there are tens of thousands of chemicals used in plastic products and an extensive review of their associated risks and hazards is beyond the scope of this article. For more information there are several reviews on the topic (Hahladakis et al., 2018; Halden, 2010; Hauser and Calafat, 
2005; Sjödin et al., 2003). Here, we will, however, provide a few examples to illustrate the potential health issues associated with chemicals in plastic products and discuss some known exposure pathways.

Most polymers, for example polyethylene (PE) and polypropylene (PP), are generally considered biologically inert. Some of the monomers and oligomers used in plastic products have, however, been shown to leach during usage and have subsequently been found in humans. Commonly mentioned examples are Bisphenol A (BPA), a monomeric building block of polycarbonate (PC), but also used as an additive in other plastics, and styrene, used in the production of polystyrene (PS) which is commonly used in styrofoam packaging. Both of these monomers are suspected endocrine disrupting chemicals (EDCs). BPA is one of the relatively few chemicals associated with plastics that have been studied extensively and it has repeatedly been reported in urine, blood, breast milk and tissue samples (Halden, 2010). The main exposure pathways are considered to be inhalation, dermal contact and ingestion (Thompson et al., 2009) and there is a growing body of evidence that many of the additional monomers, oligomers and chemicals related to plastics can adversely affect humans, with exposure being correlated to e.g. reproductive abnormalities (Lang et al., 2008; Swan, 2008; Swan et al., 2005).

One group of chemicals that is commonly used as additives in plastic consumer products are phthalates such as di-n-octyl phthalate (DnOP) and di(2-ethylhexyl) phthalate (DEHP) (Hauser and Calafat, 2005). Phthalates are associated with a wide range of health effects in animals and humans, and due to their extensive use they are often found in urine and blood samples from humans (Hauser and Calafat, 2005). Phthalates have been associated with developmental anomalies; it has for instance been shown to affect pubertal development, male and female reproductive health, pregnancy outcomes and respiratory health (reviewed in Hauser and Calafat, 2005). Moreover, the additives used as flame retardants in plastic products, including polybrominated diphenyl ethers (PBDE) and tetrabromobisphenol A (TBBPA), can be toxic. PBDE and TBBPA have both been shown to disrupt thyroid hormone homeostasis while PBDEs also exhibit anti-androgen action (Sjödin et al., 2003).

\subsection{Particle toxicity of micro- and nanoplastics}

Compared to chemicals used as plastic additives, less is known regarding the particulate toxicity effects of plastic fragments. A detailed review on potential exposure pathways, particle uptake/translocation and potential effects in humans has recently been provided by 
Wright \& Kelly (2017). As the main exposure pathways are ingestion and inhalation, particle uptake and translocation may occur in the gastrointestinal tract (GIT) and/or in the lungs. The common mechanism is thereby endocytosis; however, in the GIT persorption (the translocation of particles into the circulatory system of the GIT through gaps in the epithelium of the villus tips) is expected to constitute the major uptake route. Uptake and subsequent translocation to secondary target organs will depend on many factors, including hydrophobicity, surface charge, surface functionalization and the associated protein corona, but also particle size. The translocation of smaller particles within the GIT is likely more efficient since nano-sized PS particles have been found in blood and organs (Jani et al., 1990) while PS microparticles of $2 \mu \mathrm{m}$ only showed a low degree of translocation across the gut layer (Doyle-McCullough et al., 2007). One study has reported persorption of starch particles with a size of up to $130 \mu \mathrm{m}$ (Volkheimer, 2001), however, this was only rarely observed and the report does not provide information on the used methods. Although it is unknown whether and to what extent ingested plastic particles are translocated in a similar way, research on PE and PET wear particles stemming from the abrasion of prostheses gives some indications of potential pathways once plastic particles have crossed the GIT layer. PE particles of up to 50 $\mu \mathrm{m}$ have been found to translocate to lymph nodes and could in some cases be found in the liver and spleen (Doorn et al., 1996; Urban et al., 2000). They were associated with inflammatory responses in surrounding tissues, which include the immune activation of macrophages and the production of cytokines (Hicks et al., 1996).

More research has been conducted on particle toxicity of engineered nanoparticles (ENPs) and airborne particulate matter (PM), which shows that air pollution with small particulates is strongly associated with respiratory and cardiovascular disease (Chen et al., 2016; Stone et al., 2007). This can be related to the fact that the fraction below $2.5 \mu \mathrm{m}$ is largely retained in the lungs and can pass through respiratory barriers. The main mechanism of particle toxicity is thereby generation of oxidative stress and subsequent inflammation (Feng et al., 2016). Accordingly, the generation of reactive oxygen species (ROS) has been shown in two human cell lines (T98G and HeLa) after exposure to PE and PS particles, which did not, however, affect cell viability (Schirinzi et al., 2017). Further potential biological responses include genotoxicity, apoptosis and necrosis, which could ultimately lead to tissue damage, fibrosis and carcinogenesis (Wright and Kelly, 2017). However, the chemical composition and the particle size are decisive factors for causing adverse effects; for instance nanoparticles have been found to generate more ROS than larger particles and are more likely to be translocated 
(Stone et al., 2007). Therefore, it can be assumed that potential health effects of microplastics largely depend on the particle characteristics and that adverse effects are expected for nanoplastics rather than larger micrometer-sized plastic particles. Although the fields of ENPs and PMs provide interesting insights into mechanisms of particle toxicity, the knowledge on adverse effects of plastic particles on humans is still very limited and there is a great need for experimental data to investigate potential mechanisms.

\section{Microplastics in seafood and other products intended for human}

\section{consumption}

Plastics in seafood have made the headlines more than once and their presence is often described with expressions of concern to human health in mass media, campaigns from environmental NGOs and in scientific articles (Rochman et al., 2015; Romeo et al., 2015). The scientific studies, however, merely show the presence of microplastics in fish and bivalves and hypothesize that there may be potential adverse effects on humans. No studies have, so far, either confirmed or disproved this risk.

When discussing the exposure to microplastics through consuming seafood, it is important to consider the particle numbers that have been reported to date. For bivalves, values of $0-10.5$ plastic particles per g have been reported and Van Cauwenberghe and Janssen estimated a maximum exposure of 11000 particles per year for a European shellfish consumer (Li et al., 2015; Rochman et al., 2015; Van Cauwenberghe and Janssen, 2014). One study on readily processed fish products in the form of canned sardines and sprats reported only a maximum of 3 plastic particles per can (Karami et al., 2018), which presents a very low exposure compared to other pathways. Furthermore, the microplastics that are found in fish are mostly located within the gut (Foekema et al., 2013; Rochman et al., 2015; Romeo et al., 2015), which is rarely consumed, thus making it less likely for these particles to end up on our plates.

Seafood is not the only food product in which microplastics have been found in recent years. They have been reported in beer (Liebezeit and Liebezeit, 2014), honey, sugar (Liebezeit and Liebezeit, 2013), salt (Karami et al., 2017; Yang et al., 2015) and recently in tap water (Kosuth et al., 2017) and bottled water (Schymanski et al., 2017) (for an overview see Table S1). On this basis, estimated maximum consumptions per person per year were reported to be 4000 plastic particles from tap water (Kosuth et al., 2017) and between 37 (Karami et al., 2017) and 1000 (Yang et al., 2015) from sea salt. While results of these studies have received 
massive attention in public media, they need to be evaluated with care. The methodology that was used in the studies on honey, sugar and beer by Liebezeit \& Liebezeit (2013; 2014) was recently questioned and results were related to background contamination and potential erroneous identification of plastic particles (Lachenmeier et al., 2015). Moreover, a similar study on honey did not find a significant contamination of microplastics (Mühlschlegel et al., 2017). Also, the report on microplastics in tap water lacks a chemical/physical confirmation of the synthetic origin of the particles (Kosuth et al., 2017). A more thorough analysis has been performed in the study on bottled water, which found 14 particles/L in single-use plastic bottles and 118 particles/L in returnable plastic bottles that were traced back to originating from the bottles themselves (Schymanski et al., 2017). This indicates the importance of investigating the production and packaging processes for plastic contamination. However, the authors also report difficulties with blank samples that showed 14 particles/L on average. There are thus still many methodological and analytical uncertainties and we should be careful with generalizing from individual case studies. Further efforts are needed to develop reliable methods for sampling and analysis to avoid artefacts.

\section{The relative contribution to human exposure from different exposure pathways}

Based on the above described exposure pathways, we are here aiming at comparing the relative contributions of microplastics and associated chemicals to human exposure.

\subsection{Exposure routes for plastic-associated chemicals}

Several of the above mentioned chemicals have been reported in microplastics found in environmental samples (Fries et al., 2013) but we question the risks they posed to human health. The relatively low rate of microplastic exposure to humans, from so-far identified sources, render this pathway a relatively insignificant exposure route for these chemicals compared to other exposure pathways. BPA has, for example, been found in concentrations between 5-284 $\mu \mathrm{g} / \mathrm{kg}$ microplastics (Teuten et al., 2009) and shellfish consumers have been estimated to ingest up to 11000 microplastic particles annually (Van Cauwenberghe and Janssen, 2014). Using the measurements for the larger microplastics in the study, $20 \mu \mathrm{m}$, and assuming a cubic shape each particle would have a volume of $8000 \mu \mathrm{m}^{3}$ (or 0.000000008 $\mathrm{cm}^{3}$ ). If we then assume a density of $1.38 \mathrm{~g} / \mathrm{cm}^{3}$ (based on PET), that would give a weight/particle of $1.1 \times 10^{-8} \mathrm{~g}$, giving a total weight of $1.2 \times 10^{-4} \mathrm{~g}$ microplastics consumed per year. Using the highest concentrations of additives measured in environmental microplastics the theoretical annual human exposure would then be $3.4 \times 10^{-5} \mu \mathrm{g}$ BPA from ingesting 
microplastics in seafood. In contrast, a Swedish study estimated the mean intake per person for BPA to be $3.9 \mu \mathrm{g} /$ day (Gyllenhammar et al., 2012) which would extrapolate to $1400 \mu \mathrm{g}$ annually - almost one hundred million times higher than the above calculated annual exposure to BPA from microplastics in shellfish (Fig. 1). Although these calculations are based on several assumptions and there is a variety of additives that could be considered, it does indicate that the consumption of microplastics in shellfish is a comparatively small source of plastic-associated chemicals. EFSA made similar calculations and came to the same conclusion for BPA, PCBs and PAHs (EFSA, 2016). It is more likely that our main exposure pathways to some of these chemicals are related to consumption of food contaminated by the respective packaging, so called food contact materials. Accordingly, studies have shown a significant reduction in the urinary levels of BPA and DEHP metabolites when the participants consumed food products with limited packaging (Rudel et al., 2011). It should also be noted that as these chemicals are ubiquitous in our everyday lives, there is a wide array of exposure pathways related to our consumption patterns other than via food contact materials. There are several indications that there is a pressing need to increase awareness concerning our choices and usage of different types of plastic materials (reviewed in Halden, 2010). But as there is very limited labelling of plastic products aside from the voluntary usage of resin identification codes, there is no real possibility for consumers to make conscious choices. This puts extra weight on the governing authorities to, in the future, make responsible decisions concerning which chemicals should be allowed in plastic products.

Furthermore, microplastics are often cited to act as potential carriers of hydrophobic chemicals into water-living organisms such as fish. This statement that has recently been critiqued by researchers as 1) the chemicals often bind strongly to the plastics and 2) plastic particles likely constitute an insignificant exposure route in comparison to natural organic material in the water as well as the water itself (Koelmans et al., 2016). Although the critique rarely accounts for the potential for the material to biotransform (Watts et al., 2015) the effects of degradation and weathering (Jahnke et al., 2017; Hartmann et al., 2017), or the higher levels described at local hotspots (Hartmann et al., 2017), it illustrates the many uncertainties that surround this issue. 

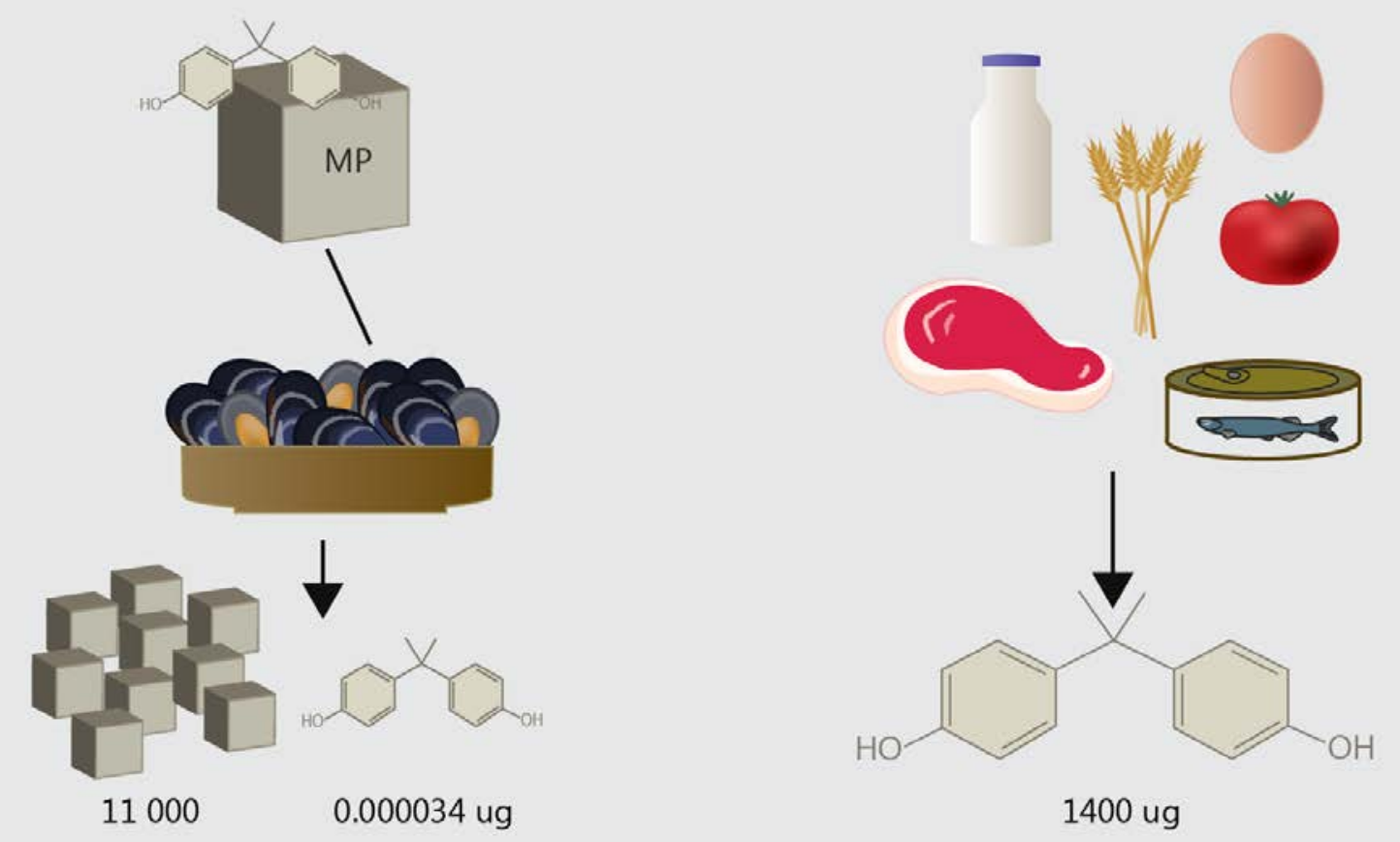

Figure 1: Based on the estimated annual ingestion of microplastics (MPs) through consuming mussels (Van Cauwenberghe and Janssen, 2014) and using the density of polyethylene terephthalate (PET) as well as the reported concentration of bisphenol A (BPA) in environmental MPs, the theoretical exposure to BPA would be in the order of 30 picogram whereas the estimated annual exposure to BPA from general food consumption is in the order of a milligrams (Gyllenhammar et al., 2012).

\subsection{Comparing exposure pathways of microplastics: food, beverages, air}

From the few studies looking on microplastics in food products and beverages, estimated maximum consumptions per person per year were reported to be 37-1000 plastic particles from sea salt (Karami et al., 2017; Yang et al., 2015), 4000 from tap water (Kosuth et al., 2017) and 11000 from shellfish (Van Cauwenberghe and Janssen, 2014). However, there are other pathways by which humans may directly be exposed to microplastics that receive less attention but are important to consider.

Plastic fibers have been reported to stem from atmospheric fallout with a deposition of up to 355 particles/ $\mathrm{m}^{2} /$ day in an urban area (Dris et al., 2016). This emphasizes not only the importance of human exposure directly from the air but also the big potential for contamination of food products and beverages with microplastics in various steps of production. The products themselves, or the processing equipment, will be air-exposed at some stage, including the plates or glasses on our dinner table. Until now very little is known 
about indoor exposure levels to airborne microplastics but at textile-processing work places levels of 500 000, 800000 and 700000 particles $/ \mathrm{m}^{3}$ have been found for nylon, polyvinylchloride (PVC) and polyester, respectively (Bahners et al., 1994). Furthermore, personal exposure levels to respirable inorganic and organic fibers from airborne dust have been monitored with personal sampling pumps and reported values for organic fibers were up to $11000 / \mathrm{m}^{3}$ for fibers $<5 \mu \mathrm{m}, 19000 / \mathrm{m}^{3}$ for fibers $>5 \mu \mathrm{m}$ and up to $2000 / \mathrm{m}^{3}$ for fibers $>20 \mu \mathrm{m}$ (Schneider et al., 1996). To investigate the potential for airborne microfiber deposition we conducted a small-scale test, in which a polyester shirt was taken off beside a water-filled beaker that stood open for $4 \mathrm{~h}$ (for a detailed description of the methods and results see SI). The water of the air-exposed beaker as well as of a blank and tap water sample were filtered and subsequently analyzed microscopically. We found a mean number of 15 synthetic fibers in the air-exposed treatment, in comparison to 4 in the tap water and 1.7 in the blanks. Due to high variability in the air-exposed treatment group, the differences between the groups were not statistically significant $(\mathrm{p}=0.06)$, although there was an apparent difference between the air-exposed group and the other two groups (Fig. S1). Nevertheless the results highlight the importance of airborne microfibers in regular indoor environments, originating from the usage of synthetic materials, as an important contribution to the total microplastic exposure pathway for humans. Furthermore, high numbers of non-synthetic fibers were found which further emphasizes the degree of background contamination of fibers in indoor environments. These numbers only provide an initial indication about airborne exposure to microplastic fibers. Systematic studies on indoor exposure levels are lacking but these first results demonstrate that airborne plastic fibers are likely to outnumber the plastic particles found in contaminated food products. Additionally, plastic materials that are used during production, transport and storage may release microplastic particles into the product as indicated by plastic packaging for drinking water (Schymanski et al., 2017).

\section{Microplastics and human health - a question of perspective}

There is extensive literature supporting the case that plastic materials can affect human health, with effects mainly related to toxicity of chemical additives that are used in plastic materials. Furthermore, a number of studies have indicated particle toxicity of plastics in the micrometer size range or smaller. Concerning the latter, the discussions on human health implications of microplastics can gain a lot from other fields that are dealing with human toxicity of particulate materials, like nanotoxicology, air pollution, fiber toxicity and wear debris from prosthetic implants. As discussed above, many of the findings from these related fields 
support the notion that micro- or nanometer sized plastic particles could adversely affect human health.

Recently, the scientific discussion within the field of microplastics research as well as the debate in public media has increasingly focused on the human health implications of microplastics in food products and beverages. There is, however, a big discrepancy between the focus and magnitude of the discussion and scientific studies. The studies that have so far been published merely show the presence of plastic particles in different environments, organisms and products intended for human consumption and are in most cases not aimed at or designed for evaluating hazards to humans. Microplastics in seafood can be used to exemplify this discrepancy: the public attention lies almost exclusively on the health implications for humans who consume these organisms, while the scientific focus is mostly on the effects that this may have on the organisms themselves. While the latter has a stronger scientific background (Lu et al., 2016; Mattsson et al., 2015; Paul-Pont et al., 2016; Rochman et al., 2013; von Moos et al., 2012; Wright et al., 2013), it has not gained the same traction. Of course, it is important to address the broader implications that the presence of microplastics in aquatic organisms may have, also including humans, but we need to be careful with speculations that extrapolate far beyond the scientific findings. There seems to be a trend for overhasty conclusions on microplastics in food products, which are quickly picked up by the public media and shape a distorted picture of the issue of microplastics in comparison to the scientific literature. Plastic pollution gains a lot of public attention which attenuates the need for clear communication and transparency even further. Natural scientists play an important role in identifying and describing problematic changes in the environment, or in terms of human health. We can then convey our collective knowledge to other actors in society in order to address and mitigate environmental problems. As scientists, we have a moral obligation to present the current state of knowledge as correctly and accurately as possible.

Furthermore, there is an imbalance in the discussion on human exposure to microplastics as it is rarely put into perspective via comparisons with other exposure routes. As shown above, most of the exposures are likely to stem from our consumption and everyday use of plastic materials and products. The current discourse seems to be a symptom of a systematic failure to see the overall picture related to plastic consumption resulting in a skewed risk perception where an individual may become outraged when finding out that there are plastic particles in fish but not reflect on the plastic container that the fish reaches our house in. There is also a palpable difference in the current debate concerning the threat of microplastics, versus the 
hazards associated with plastic materials and associated chemicals. Plastic pollution is well described and known to be associated with large socioeconomic costs and adverse environmental effects. Because it is tangible and easily communicated, it has helped spark several solution-based initiatives and important discussions on issues related to environmental pollution. Concerning microplastics, the current knowledge on adverse effects is marginal compared to the knowledgebase of chemical effects, which spans decades, generations and populations. Even so, the effects of chemical pollutants are often discussed to a much lesser extent in the public. And ironically, while there is widespread concern for the effects of microplastics, there is comparatively little debate addressing our current large scale usage of plastic materials, their impacts in the environment and for human health, and their role in consumerism and economy.

To avoid this inconsistency, it is important that we take a more holistic viewpoint on plastics and human health risks. It is possible that the fibers in the tap water may affect human health and it is alarming that plastic fibers and particles are found almost everywhere, but it is important to put this into the perspective relating to our own consumption. This will feed into polymer research and development, and facilitate solutions and the necessary changes in waste management, chemical legislation and our current overconsumption of plastic products. These three important factors are incidentally also among the main root causes of plastic pollution in the environment.

Thus, we urge for a more nuanced debate within the scientific community. In order to achieve that it is important to study and evaluate potential human health effects but these studies need to take exposure through our general consumption of plastic materials into account. The relative importance of different exposure pathways needs to be considered and future studies should also include the environmental contamination of various consumer products. The interpretation of related findings however needs to maintain a broad perspective. We also emphasize that it is important that the debate moving forward incorporates the bigger perspectives concerning global production and usage of plastics and chemicals to a greater extent.

\section{Acknowledgement}

For financial support of Therese M. Karlsson we thank the Swedish Environmental Research Council Formas 2014-1146, and the Interreg project Clean Coastline. We furthermore would 
like to thank the Technical University of Denmark for funding through the DTU-EPFL collaborative PhD grant of Sinja Rist as well as the Otto Mønsteds Fond for supporting her external research stay at Sven Lovén Centre for Marine Sciences. Bethanie Carney Almroth was supported by the Swedish Environmental Research Council Formas 2016-00895. We would also like to acknowledge the KVA grant for Internationalization and Scientific Renewal at the Sven Lovén Centre for Marine Sciences for their support to Nanna B. Hartmann in the project Microplastics in Marine Bivalves. The funding sources had no involvement in study design, collection and interpretation of data or writing of the report.

\section{References}

Andrady, A.L., 2011. Microplastics in the marine environment. Mar. Pollut. Bull. 62, 15961605. doi:10.1016/j.marpolbul.2011.05.030

Andrady, A.L., Neal, M.A., 2009. Applications and societal benefits of plastics. Philos. Trans. R. Soc. B Biol. Sci. 364, 1977-1984. doi:10.1098/rstb.2008.0304

Bahners, T., Ehrler, P., Hengstberger, M., 1994. Erste Untersuchungen zur Erfassung und Charakterisierung textiler Feinstäube. Melliand Textilberichte 24-30.

Browne, M.A., Crump, P., Niven, S.J., Teuten, E., Tonkin, A., Galloway, T., Thompson, R., 2011. Accumulation of Microplastic on Shorelines Woldwide: Sources and Sinks. Environ. Sci. Technol. 45, 9175-9179. doi:10.1021/es201811s

Chen, R., Hu, B., Liu, Y., Xu, J., Yang, G., Xu, D., Chen, C., 2016. Beyond PM2.5: The role of ultrafine particles on adverse health effects of air pollution. Biochim. Biophys. Acta Gen. Subj. 1860, 2844-2855. doi:10.1016/j.bbagen.2016.03.019

Dehaut, A., Cassone, A.-L., Frère, L., Hermabessiere, L., Himber, C., Rinnert, E., Rivière, G., Lambert, C., Soudant, P., Huvert, A., Duflos, G., Paul-Pont, I., 2016. Microplastics in seafood : Benchmark protocol for their extraction and. Environ. Pollut. 215, 223-233. doi:10.1016/j.envpol.2016.05.018

Doorn, P.F., Campbell, P.A., Amstutz, H.C., 1996. Metal Versus Polyethylene Wear Particles in Total Hip Replacements: A Review. Clin. Orthop. Relat. Res. 329.

Doyle-McCullough, M., Smyth, S.H., Moyes, S.M., Carr, K.E., 2007. Factors influencing intestinal microparticle uptake in vivo. Int. J. Pharm. 335, 79-89. doi:10.1016/j.ijpharm.2006.10.043

Dris, R., Gasperi, J., Saad, M., Mirande, C., Tassin, B., 2016. Synthetic fibers in atmospheric fallout: A source of microplastics in the environment? Mar. Pollut. Bull. 4-7. 
doi:10.1016/j.marpolbul.2016.01.006

EFSA, 2016. Presence of microplastics and nanoplastics in food, with particular focus on seafood. EFSA J. 14. doi:10.2903/j.efsa.2016.4501

Feng, S., Gao, D., Liao, F., Zhou, F., Wang, X., 2016. The health effects of ambient PM2.5 and potential mechanisms. Ecotoxicol. Environ. Saf. 128, 67-74. doi:10.1016/j.ecoenv.2016.01.030

Foekema, E.M., De Gruijter, C., Mergia, M.T., van Franeker, J.A., Murk, A.J., Koelmans, A. a, 2013. Plastic in North Sea Fish. Environ. Sci. Technol. 47, 130711150255009. doi:10.1021/es400931b

Fries, E., Dekiff, J.H., Willmeyer, J., Nuelle, M.-T., Ebert, M., Remy, D., 2013. Identification of polymer types and additives in marine microplastic particles using pyrolysis-GC/MS and scanning electron microscopy. Environ. Sci. Process. Impacts 15, 1949. doi:10.1039/c3em00214d

GESAMP, 2015. Sources, Fate and Effects of Microplastics in the Marine Environment: A Global Assessment. Reports Stud. GESAMP 90, 96. doi:10.13140/RG.2.1.3803.7925

Gyllenhammar, I., Glynn, A., Darnerud, P.O., Lignell, S., van Delft, R., Aune, M., 2012. 4Nonylphenol and bisphenol A in Swedish food and exposure in Swedish nursing women. Environ. Int. 43, 21-28. doi:10.1016/j.envint.2012.02.010

Hahladakis, J.N., Velis, C.A., Weber, R., Iacovidou, E., Purnell, P., 2018. An overview of chemical additives present in plastics: Migration, release, fate and environmental impact during their use, disposal and recycling. J. Hazard. Mater. 344, 179-199. doi:10.1016/j.jhazmat.2017.10.014

Halden, R.U., 2010. Plastics and Health Risks. Annu. Rev. Public Health 31, 179-194. doi:10.1146/annurev.publhealth.012809.103714

Hartmann, N.B., Rist, S., Bodin, J., Jensen, L.H., Schmidt, S.N., Mayer, P., Meibom, A., Baun, A., 2017. Microplastics as vectors for environmental contaminants: Exploring sorption, desorption, and transfer to biota. Integr. Environ. Assess. Manag. 13, 488-493. doi:10.1002/ieam.1904

Hastings, E., Potts, T., 2013. Marine litter: Progress in developing an integrated policy approach in Scotland. Mar. Policy 42, 49-55. doi:10.1016/j.marpol.2013.01.024

Hauser, R., Calafat, A.M., 2005. Phthalates and Human Health. Occup. Environ. Med. 62, 806-818. doi:10.1136/oem.2004.017590

Hicks, D.G., Judkins, A.R., Sickel, J.Z., Rosier, R.N., Puzas, J.E., Keefe, R.J.O., 1996. Granular histiocytosis of pelvic lymph nodes following total hip arthroplasty . The 
presence of wear debris , cytokine ... Granular Histiocytosis of Pelvic Lymph Nodes following Total Hip Arthroplasty. J. Bone Jt. Surg. 482-496.

Jahnke, A., Arp, H.P.H., Escher, B.I., Gewert, B., Gorokhova, E., Kühnel, D., Ogonowski, M., Potthoff, A., Rummel, C., Schmitt-Jansen, M., Toorman, E., MacLeod, M., 2017. Reducing Uncertainty and Confronting Ignorance about the Possible Impacts of Weathering Plastic in the Marine Environment. Environ. Sci. Technol. Lett. 4, 85-90. doi:10.1021/acs.estlett.7b00008

Jani, P., Halbert, G.W., Langridge, J., Florence, A.T., 1990. Nanoparticle Uptake by the Rat Gastrointestinal Mucosa: Quantitation and Particle Size Dependency. J. Pharm. Pharmacol. 42, 821-826. doi:10.1111/j.2042-7158.1990.tb07033.x

Karami, A., Golieskardi, A., Choo, C.K., Larat, V., Karbalaei, S., Salamatinia, B., 2018. Microplastic and mesoplastic contamination in canned sardines and sprats. Sci. Total Environ. 612, 1380-1386. doi:10.1016/j.scitotenv.2017.09.005

Karami, A., Golieskardi, A., Keong Choo, C., Larat, V., Galloway, T.S., Salamatinia, B., 2017. The presence of microplastics in commercial salts from different countries. Sci. Rep. 7, 46173. doi:10.1038/srep46173

Koelmans, A.A., Bakir, A., Burton, G.A., Janssen, C.R., 2016. Microplastic as a Vector for Chemicals in the Aquatic Environment: Critical Review and Model-Supported Reinterpretation of Empirical Studies. Environ. Sci. Technol. 50, 3315-3326. doi:10.1021/acs.est.5b06069

Koelmans, A.A., Besseling, E., Foekema, E., Kooi, M., Mintenig, S., Ossendorp, B.C., Redondo-Hasselerharm, P.E., Verschoor, A., van Wezel, A.P., Scheffer, M., 2017. Risks of Plastic Debris: Unravelling Fact, Opinion, Perception, and Belief. Environ. Sci. Technol. acs.est.7b02219. doi:10.1021/acs.est.7b02219

Korzun, E.A., Heck, H.H., 1990. Sources and Fates of Lead and Cadmium in Municipal Solid Waste. J. Air Waste Manage. Assoc. 40, 1220-1226. doi:10.1080/10473289.1990.10466766

Kosuth, M., Wattenberg, E. V., Mason, S.A., Tyree, C., Morrison, D., 2017. Synthetic polymer contaminating global drinking water [WWW Document]. URL https://orbmedia.org/stories/Invisibles_final_report

Lachenmeier, D.W., Kocareva, J., Noack, D., Kuballa, T., 2015. Microplastic identification in German beer - an artefact of laboratory contamination? Dtsch. Leb. 111, 437-440.

Landrigan, P.J., Fuller, R., Acosta, N.J.R., Adeyi, O., Arnold, R., Basu, N. (Nil), Baldé, A.B., Bertollini, R., Bose-O’Reilly, S., Boufford, J.I., Breysse, P.N., Chiles, T., Mahidol, C., 
Coll-Seck, A.M., Cropper, M.L., Fobil, J., Fuster, V., Greenstone, M., Haines, A., Hanrahan, D., Hunter, D., Khare, M., Krupnick, A., Lanphear, B., Lohani, B., Martin, K., Mathiasen, K. V., McTeer, M.A., Murray, C.J.L., Ndahimananjara, J.D., Perera, F., Potočnik, J., Preker, A.S., Ramesh, J., Rockström, J., Salinas, C., Samson, L.D., Sandilya, K., Sly, P.D., Smith, K.R., Steiner, A., Stewart, R.B., Suk, W.A., van Schayck, O.C.P., Yadama, G.N., Yumkella, K., Zhong, M., 2017. The Lancet Commission on pollution and health. Lancet 6736. doi:10.1016/S0140-6736(17)32345-0

Lang, I.A., Galloway, T.S., Scarlett, A., Henley, W.E., Depledge, M., Wallace, R.B., Melzer, D., 2008. Association of Urinary Bisphenol A Concentration With Medical Disorders and Laboratory. JAMA 300, 1303-1310. doi:10.1001/jama.300.11.1303

Lassen, C., Hansen, S.F., Magnusson, K., Norén, F., Hartmann, N.B., Jensen, P.R., Nielsen, T.G., Brinch, A., 2015. Microplastics: Occurrence, effects and sources of releases to the environment in Denmark. Copenhagen K: Danish Environmental Protection Agency.

Lattin, G.L., Moore, C.J., Zellers, A.F., Moore, S.L., Weisberg, S.B., 2004. A comparison of neustonic plastic and zooplankton at different depths near the southern California shore. Mar. Pollut. Bull. 49, 291-294. doi:10.1016/j.marpolbul.2004.01.020

Li, C.-T., Zhuang, H.-K., Hsieh, L.-T., Lee, W.-J., Tsao, M.-C., 2001. PAH emission from the incineration of three plastic wastes. Environ. Int. 27, 61-67. doi:10.1016/S01604120(01)00056-3

Li, J., Yang, D., Li, L., Jabeen, K., Shi, H., 2015. Microplastics in commercial bivalves from China. Environ. Pollut. 207, 190-195. doi:10.1016/j.envpol.2015.09.018

Li, W.C., Tse, H.F., Fok, L., 2016. Plastic waste in the marine environment: A review of sources, occurrence and effects. Sci. Total Environ. 566-567, 333-349. doi:10.1016/j.scitotenv.2016.05.084

Liebezeit, G., Liebezeit, E., 2014. Synthetic particles as contaminants in German beers. Food Addit. Contam. Part A 31, 1574-1578. doi:10.1080/19440049.2014.945099

Liebezeit, G., Liebezeit, E., 2013. Non-pollen particulates in honey and sugar. Food Addit. Contam. Part A 30, 2136-2140. doi:10.1080/19440049.2013.843025

Lu, Y., Zhang, Y., Deng, Y., Jiang, W., Zhao, Y., Geng, J., Ding, L., Ren, H., 2016. Uptake and Accumulation of Polystyrene Microplastics in Zebrafish ( Danio rerio ) and Toxic Effects in Liver. Environ. Sci. Technol. 50, 4054-4060. doi:10.1021/acs.est.6b00183

Mattsson, K., Ekvall, M.T., Hansson, L., Linse, S., Malmendal, A., Cedervall, T., 2015. Altered Behavior, Physiology, and Metabolism in Fish Exposed to Polystyrene Nanoparticles. Environ. Sci. Technol. 49, 553-561. doi:10.1021/es5053655 
Menad, N., Björkman, B., Allain, E.G., 1998. Combustion of plastics contained in electric and electronic scrap. Resour. Conserv. Recycl. 24, 65-85. doi:10.1016/S09213449(98)00040-8

Mühlschlegel, P., Hauk, A., Walter, U., Sieber, R., 2017. Lack of evidence for microplastic contamination in honey. Food Addit. Contam. Part A 34, 1982-1989. doi:10.1080/19440049.2017.1347281

NOLAN-ITU, 2002. Plastic Shopping Bags - Analysis of Levies and Environmental Impacts. Dep. Environ. Heritage. Environ. Aust. 102.

Paul-Pont, I., Lacroix, C., González Fernández, C., Hégaret, H., Lambert, C., Le Goïc, N., Frère, L., Cassone, A.-L., Sussarellu, R., Fabioux, C., Guyomarch, J., Albentosa, M., Huvet, A., Soudant, P., 2016. Exposure of marine mussels Mytilus spp. to polystyrene microplastics: Toxicity and influence on fluoranthene bioaccumulation. Environ. Pollut. 1-14. doi:10.1016/j.envpol.2016.06.039

Rochman, C.M., Hoh, E., Kurobe, T., Teh, S.J., 2013. Ingested plastic transfers hazardous chemicals to fish and induces hepatic stress. Sci. Rep. 3, 3263. doi:10.1038/srep03263

Rochman, C.M., Tahir, A., Williams, S.L., Baxa, D. V., Lam, R., Miller, J.T., Teh, F.-C., Werorilangi, S., Teh, S.J., 2015. Anthropogenic debris in seafood: Plastic debris and fibers from textiles in fish and bivalves sold for human consumption. Sci. Rep. 5, 14340. doi:10.1038/srep14340

Romeo, T., Pietro, B., Pedà, C., Consoli, P., Andaloro, F., Cristina, M., 2015. First evidence of presence of plastic debris in stomach of large pelagic fish in the Mediterranean Sea. Mar. Pollut. Bull. 95, 358-361. doi:10.1016/j.marpolbul.2015.04.048

Rudel, R.A., Gray, J.M., Engel, C.L., Rawsthorne, T.W., Dodson, R.E., Ackerman, J.M., Rizzo, J., Nudelman, J.L., Brody, J.G., 2011. Food Packaging and Bisphenol A and Bis(2-Ethyhexyl) Phthalate Exposure: Findings from a Dietary Intervention. Environ. Health Perspect. 119, 914-920. doi:10.1289/ehp.1003170

Schirinzi, G.F., Pérez-Pomeda, I., Sanchís, J., Rossini, C., Farré, M., Barceló, D., 2017. Cytotoxic effects of commonly used nanomaterials and microplastics on cerebral and epithelial human cells. Environ. Res. 159, 579-587. doi:10.1016/j.envres.2017.08.043

Schneider, T., Burdett, G., Martinon, L., Brochard, P., Guillemin, M., Teichert, U., Draeger, U., 1996. Ubiquitous fiber exposure in selected sampling sites in Europe. Scand. J. Work. Environ. Heal. 22, 274-284.

Schymanski, D., Goldbeck, C., Humpf, H., Fürst, P., 2017. Analysis of microplastics in water by micro-Raman spectroscopy: Release of plastic particles from different packaging into 
mineral water. Water Res. doi:10.1016/j.watres.2017.11.011

Seltenrich, N., 2015. New link in the food chain? Marine plastic pollution and seafood safety. Environ. Health Perspect. 123, 34-42.

Sjödin, A., Patterson, D.G., Bergman, Å., 2003. A review on human exposure to brominated flame retardants?particularly polybrominated diphenyl ethers. Environ. Int. 29, 829-839. doi:10.1016/S0160-4120(03)00108-9

Stone, V., Johnston, H., Clift, M.J.D., 2007. Air Pollution, Ultrafine and Nanoparticle Toxicology: Cellular and Molecular Interactions. IEEE Trans. Nanobioscience 6, 331340. doi:10.1109/TNB.2007.909005

Swan, S.H., 2008. Environmental phthalate exposure in relation to reproductive outcomes and other health endpoints in humans. Environ. Res. 108, 177-184. doi:10.1016/j.envres.2008.08.007

Swan, S.H., Main, K.M., Liu, F., Sara, L., Kruse, R.L., Calafat, A.M., Catherine, S., Redmon, J.B., Ternand, C.L., Teague, J.L., 2005. Decrease in anogenital distance among male infants with prenatal phthalate exposure. Environ. Health Perspect. 8100. doi:10.1289/ehp.8100

Talsness, C.E., Andrade, A.J.M., Kuriyama, S.N., Taylor, J.A., vom Saal, F.S., 2009. Components of plastic: experimental studies in animals and relevance for human health. Philos. Trans. R. Soc. B Biol. Sci. 364, 2079-2096. doi:10.1098/rstb.2008.0281

Teuten, E.L., Saquing, J.M., Knappe, D.R.U., Barlaz, M.A., Jonsson, S., Bjorn, A., Rowland, S.J., Thompson, R.C., Galloway, T.S., Yamashita, R., Ochi, D., Watanuki, Y., Moore, C., Viet, P.H., Tana, T.S., Prudente, M., Boonyatumanond, R., Zakaria, M.P., Akkhavong, K., Ogata, Y., Hirai, H., Iwasa, S., Mizukawa, K., Hagino, Y., Imamura, A., Saha, M., Takada, H., 2009. Transport and release of chemicals from plastics to the environment and to wildlife. Philos. Trans. R. Soc. B Biol. Sci. 364, 2027-2045. doi:10.1098/rstb.2008.0284

Thompson, R.C., Moore, C.J., Saal, F.S., Swan, S.H., 2009. Plastics, the environment and human health : current consensus and future trends. Philos. Trans. R. Soc. B Biol. Sci. 364, 2153-2166. doi:10.1098/rstb.2009.0053

UNEP, 2016. Marine debris: understanding, preventing and mitigating the significant adverse impacts on marine and coastal biodiversity, Secretariat of the Convention on Biological Diversity, Montreal. doi:10.1080/14888386.2007.9712830

Urban, R.M., Jacobs, J.J., Tomlinson, M.J., Gavrilovic, J., Black, J., Peoch, M., 2000. Dissemination of wear particles to the liver, spleen, and abdominal lymph nodes of 
patients with hip or knee replacement. J. Bone Jt. Surg. 82-A.

Van Cauwenberghe, L., Janssen, C.R., 2014. Microplastics in bivalves cultured for human consumption. Environ. Pollut. 193, 65-70. doi:10.1016/j.envpol.2014.06.010

van Sebille, E., Wilcox, C., Lebreton, L., Maximenko, N., Hardesty, B.D., van Franeker, J.A., Eriksen, M., Siegel, D., Galgani, F., Law, K.L., 2015. A global inventory of small floating plastic debris. Environ. Res. Lett. 10, 124006. doi:10.1088/17489326/10/12/124006

van Wezel, A., Caris, I., Kools, S., 2015. Release of primary microplastics from consumer products to wastewater in The Netherlands. Environ. Toxicol. Chem. n/a-n/a. doi:10.1002/etc.3316

Volkheimer, G., 2001. The phenomenon of persorption: persorption, dissemination, and elimination of microparticles, in: Old Hebron University Seminar Monography 14: Intestinal Translocation. pp. 7-17.

von Moos, N., Burkhardt-Holm, P., Köhler, A., 2012. Uptake and Effects of Microplastics on Cells and Tissue of the Blue Mussel Mytilus edulis L. after an Experimental Exposure. Environ. Sci. Technol. 46, 11327-11335. doi:10.1021/es302332w

Watts, A.J.R., Urbina, M.A., Corr, S., Lewis, C., Galloway, T.S., 2015. Ingestion of Plastic Microfibers by the Crab Carcinus maenas and Its Effect on Food Consumption and Energy Balance. Environ. Sci. Technol. 49, 14597-14604. doi:10.1021/acs.est.5b04026

Wright, S.L., Kelly, F.J., 2017. Plastic and Human Health: A Micro Issue? Environ. Sci. Technol. 51, 6634-6647. doi:10.1021/acs.est.7b00423

Wright, S.L., Thompson, R.C., Galloway, T.S., 2013. The physical impacts of microplastics on marine organisms: A review. Environ. Pollut. 178, 483-492.

doi:10.1016/j.envpol.2013.02.031

Yang, D., Shi, H., Li, L., Li, J., Jabeen, K., Kolandhasamy, P., 2015. Microplastic Pollution in Table Salts from China. Environ. Sci. Technol. 49, 13622-13627. doi:10.1021/acs.est.5b03163 